\author{
Research Article \\ (c) 2020 Chieme Azubuike and Nwokezi John Ikoro. \\ This is an open access article licensed under the Creative Commons \\ Attribution-NonCommercial 4.o International License \\ (https://creativecommons.org/licenses/by-nc/4.0/)
}

Received: 3 November 2019 / Revised: 16 December 2019 / Accepted: 22 December 2019 / Published: 10 January 2020

\title{
A Comparative Study of Urban and Rural Youths' Exposure to Violence in TV Programmes and Susceptibility to Violent Behaviour
}

\author{
Chieme Azubuike \\ Department of Mass Communication, \\ Captain Elechi Amadi Polytechnic, \\ Rumuola 100oo1, Port Harcourt, Rivers State, Nigeria \\ Nwokezi John Ikoro \\ Department of Mass Communication, \\ Captain Elechi Amadi Polytechnic, \\ Rumuola 100oo1, Port Harcourt, Rivers State, Nigeria
}

Doi: 10.36941/mjss-2020-0o13

\begin{abstract}
Television as an agent of education and dissemination of information has touched lives in diverse aspects, especially in education, entertainment and enlightenment. However, even though it parades these positive attributes, it has also encouraged negative attributes to the audience, especially the youths. Youths are susceptible to violence arising from watching TV. Then, the question is who are the most hit by this anomaly - the urban or the rural youth? This is the main thrust of this study. To unravel answers to this question, this study used the survey method where the use of questionnaire was employed. The findings show that the urban youths are more vulnerable to violence due to TV viewing. We therefore, recommend that the parents should guard their children on what to watch; friends to keep. Above all, agencies of government should intensify efforts at making sure that guidelines to dishing out films are adhered to.
\end{abstract}

Keywords: Comparative, Vulnerability, Television, Violence, Youths, Urban, Rural

\section{Introduction}

The emergence of television, decades ago, speaks unimaginable volumes and uncountable impacts on the heterogeneous audience the world over. Television parades lots of benefits which ranges from education, information and entertainment. Television is unarguably a powerful teaching apparatus which enhances understanding of other people's belief, ways of life, culture; ordinarily we may not have visited.

Rodman (2006, p. 273) opines that "from the beginning, educators, and industry leaders all agree that television would be a wonderful medium of education". Advancing further on the foregoing scenario, Dominick (2007, p.232) described television as a tool for dissemination of information through several means like news and programmes etc. He notes further that

Television has become the dominant medium for, news and entertainment... surveys have consistently revealed that most people choose television as their main source of news... prime-time television series 
may draw an audience of 20 million household. In short, TV has become an important part of our society (Dominick, 2007, p.232).

The audio-visual features of television made it the most patronized medium of communication by both adults and children. Initially, people may wish to watch television for leisure, but gradually they get engrossed and attached to it. Instructively, children/youths as shown by expert researches can watch television for hours. Through it, they learn about new ways of reasoning, new behavior and above all, new approach to life generally. Most of the lessons derivable from television may be positive or negative. Against the foregoing background, Michael Novak, a social critic says that television is a moulder of the soul's geography. It builds up incrementally a psychic structure of expectations.

Vivian (2007, p.173) recognizes television as a socialization agent from where young ones learn about social norms. There has been so much debate on the fact that most behavior exhibited by children and youths are learnt from television. Vivian further adds that, while this may not be entirely true, records are replete with cases of what television has done to the growing minds who find it difficult to differentiate between reality and effect (trick) on television, thereby susceptible to violence due to what they watch.

Therefore, the impact of television and its underlying properties increased tremendously following the invention of video machines and information communication technologies through the computer and telephones which can play back recorded events before or after it was relayed and, liberty to watch what one likes without necessarily waiting for a television station to transmit such a programme again.

Children and youths, from diverse sources have access to information and materials which could be dangerous. In fact, most children take whatever they see on television as good and acceptable, even if it is violent, immoral and dangerous. The danger in this is that after watching these things, they discuss it in group and consolidate on what they had watched to the extent of trying out the possibilities of replicating the feat.

The effects of these impacts are predominantly visible on the youths and children arising from the fact that they are too young in mind and too tender to decipher between facts from fantasy. This leads to their exhibition of those learned behavior garnered from the television to the general public. The public are permanently at the receiving end, as they practice and ventilate these negative traits on them. This raises a question of; is television and all it parades portend a curse or a blessing? Television is watched by those in the urban and rural areas. Now, after watching; which of the youths acquire violence traits arising from television viewing the more? - Those in urban or rural areas? Do they actually exhibit these traits on the public? This is the crux of this study as it tries to find out whether the urban or rural youths are more susceptible to the influence of television violence. Secondly, the study sets out to determine if youths in urban areas exhibit traits of violence learnt on TV in real life than their rural counterparts.

\section{$1.1 \quad$ Statement of Problem}

According to Potter and Tamasello (2010) exposure to violence on television translates to the manifestation of some level of violence in real life. Experiments conducted provided evidence of this effect, which successfully documented the occurrence of several negative effects, linking these effects to particular factors is the portrayals as filtered through various meditating factors.

This was the prevalent scenario among the television outfits, which the various audience continuously had no choice than to imbibe and view on daily basis to the extent that the earlier qualities of television like information, education and entertainment went into other programmes depicting and portraying other attributes which only debased the populace and enriched them with less positive educative programming. Thus, programming became synonymous with violence and its concomitant qualities or effects. No wonder, Awake (2006, p.4) writes 
Much of the programming however is neither wholesome nor educational in nature. Probably, the most impassioned criticism comes from people who decry TV's abundant arid graphic. One study in the United States for example, found that nearly 2 out of 3 TV programs contain scenes of violence, averaging six per hour. By the time a youth reached adulthood, he will have watched thousands of dramatized acts of violence and murder, sexual content too in an abundant supply two thirds of all TV programs include talk about sex and 35 percent include sexual behavior.

So, children, youths and adults are engulfed in this situation, as they are always playing out the inherent attributes handed down by television programmes. Arising from the above situation, these youths exhibit numerous traits like cigarette smoking, proficient handling of guns, bullying, cultism, gangterism, extortion, assault, insult etc. largely due to these exposure to television programmes, and given that they find it difficult to abandon what they watched, and toe the line of just being a mere watcher due to their age.

It is for this reason, therefore, that this study intends to unravel some salient questions concerning this research and these include: Are the urban youths prone to violence due -to television viewing than their rural counterparts? Secondly, do youths in urban areas exhibit traits portrayed on TV on unsuspected members of the public than their rural counterparts?

Above all, the general consensus is that activities of these violent films and programmes are affecting the mode of lives of the people particularly the young ones as well as the criminally minded persons. So, who are most affected among the youths in the urban or rural? This is therefore the main thrust of this study.

\subsection{Objectives of Study}

The objectives of this study are;

(i) To establish the extent to which urban and rural youth's are exposed to Tv programmes.

(ii) To ascertain if urban youths are more prone to violence than their rural counterparts via TV viewership.

(iii)To find out if youths in urban areas exhibit traits portrayed on TV on members of the public than their rural counterparts.

(iv) To ascertain the extent of effect TV violence has on youth's behaviour in urban and rural areas.

\section{Literature Review}

In this segment of the study, related literature to the research topic will be reviewed. Among which are related studies, seminar papers, workshop papers, books and web materials.

\subsection{Youths, Television and Vulnerability}

According to Jeffrey, Cohen, Smaites, Kasen, \& Brook (n.d), television carries lots of violent portrayals. It tends to boost aggressiveness in man. This has been made evident, especially by various studies relating to youths and television violence. As a matter of concern, three to five violent acts are depicted in an average hour of prime time television and $20-25$ violent arts are depicted in an average hour of children/youth television. Research has indicated that viewing television is associated with aggressive behaviour.

It is the youths who are in the limelight of viewing violence. They are energetic and ever ready to show vigour and strength. According to Cambridge International Dictionary of English as cited by Chieme and Usua, (2008, p.219) describes the youth as;

That vibrant segment of the population with the capacity to take over from current leaders. This is irrespective of their present age bracket. A youth can be a teenager, or one in early adulthood. They are 
the people 'imbued with relentless energy, vigour and drive. The youth of any society are tomorrow's leaders and the future of that society depends on the quality of the youths in the society.

The duo went on to assert that the term youth is usually described in relative sense. Thus, in this context of youths and TV violence, the youth fits in exactly how they described it vis-à-vis television, youths and violence.

Television and film, therefore, have become major players in the attitude of youths in Nigeria in terms of behaviour and attitudinal changes. Films on TV, which is the fulcrum on which youths exhibit some of their traits have impacted on the youths, thus, the film and broadcast industry work hand in hand to deliver this crucial partnership function.

Thus, vulnerability to television viewing vis-à-vis violence among youths has been a major concern among stakeholders, the world over which ranges from adolescence to adulthood. It is why Jeffrey et al, (n.d), explains that, there was a significant association between the amount of time spent watching television during adolescence and early adulthood and livelihood of subsequent aggressive acts against others.

Imperatively, television viewing of aggressive programmes invariably increases the extent at which youths imbibe aggression generally. In fact, research has indicated that viewing television violence is associated with aggressive behaviour.

\subsection{Youths, Viewing, Aggression and Causes}

It is true that most violence are the result of television viewing of violent programmes, but more than that, there are other causes of violent behaviour which may encourage the violence, especially combined with viewing and learned behaviour due to environment. No wonder, Science online (www.sciencemag.org/cgi/content/full/295/5564/2468/clci) exemplifies the causes of violence and later aggravated by TV viewing this way;

"Childhood neglect, growing up in an unsafe neigbourhood, low family income, low parental education and psychiatric disorders were significantly associated with time spent watching television at mean age 14 and with aggressive behaviour reported at mean age 16 or 22."

More striking revelations abound on the causes of violence as Noguera (2010), establishes that; the effort to identify the cause of youth violence has focused on a set of variables conceived as risk factors that are associated with violent behaviour. These factors include the influence of social or cultural forces emanating from the neighbourhood/ community school, peers, and family.

More than anything else, it is instructive to identify the fact that violence is basically a learned behaviour, which confirms therefore that it could be learnt from the viewing of television, which is usually (consciously or unconsciously) reinforced by families through child - rearing practices or promoted by the media and other expression of popular culture through subtle and blatant images.

Unarguably, it is evident that the media via the expression of images promote these forms of learned violence. It is worthy of note to say that there are consequences of these violence in behaviour on the society. Hence, Nouguera maintains that "time spent watching television during adolescence was associated with risk for subsequent aggressive acts among youths with and without a history of aggressive behaviour. In the same vein, young people are not only increasingly more likely to be perpetrators of violence, but are also much more likely to be the victims of violent crime. These occur in diverse ways than one. For instance, there is the preponderance of assault or physical fights resulting in injury; Robbery, threats to injure someone, or weapon used to commit a crime; any aggressive act against other persons. The melting of this aggressive behaviour on people could be on strangers, friends, siblings, peers and others who eventually falls victims to the aggressive ones.

Against the foregoing, there are those who may be basically vulnerable to the consequences of violent television viewing. According to Donohue, Henke \& Morgan (1988) this class of vulnerable viewer includes: children from minority and immigrant groups, children who are emotionally 
disturbed or who have learning disabilities, children who are abused by parents, families in distress.

Evidently, no matter the magnitude, these crimes and violence, arising from Television viewing are prevalent in both the urban and rural residents. The vulnerability of violence is measured by the degree of the exhibition of certain traits garnered from the programmers on television.

As an attempt to unravel the level of vulnerability, lots of scholars have presented contributions and many others have made imprints on this topical issue; but there are areas concerning the topic that needs to be addressed and that is the comparative study of urban and rural youths' exposure to violence in Tv prgrammes and susceptibility to violent behaviour. It is therefore, why this study is salient, basically to ascertain the youths who are the worst hit in TV viewing and violence in Rivers State, Nigeria.

\subsection{Theoretical Framework}

\subsubsection{Cultivation Theory}

This study is anchored on the cultivation theory. The cultivation theory is relevant to this study in that it proposes that the more time viewers spend watching television, the more likely their perception of social reality will reflect what they see on television. Saito, (2007, p.512) Cultivation theory was developed by George Gerbner, L. Gross and M. Morgan in 1976. According to Morgan and Saito (2007) as cited by Chieme and Usua (2008, p.221), it is believed that when people get continually exposed to certain television programme, all of them who do so tend to think or behave alike, and their behaviour tilt towards the traits displayed by actors in the television programme.

It is important to note that the cultivation theory proposes that television among other media genre imposes grave influence on diverse audience through the changing of the audience perception of the realities of life. Thus, television viewing has great effect on the audience, which greatly envelopes other forms of information, thereby arousing cultivation of these attributes associated with values and roles.

The cultivation theory, according to Baran (2009) has been applied to countless other television - cultivated realities such as beauty, sex, roles, religion, the judicial process, and message. This means that television cultivates realities, especially for big time viewing audience.

The application of this theory to the study is that youth's behaviour and consequent exhibition of the traits acquired from the TV viewing of violent Programme are aided and aggravated by the fact that they are exposed to violence because of what they watch on TV thereby cultivating the attitude, behaviour and attributes. Thus, when they are exposed to violence arising from TV viewing; they also cultivate the attributes and carry it along the same way they saw them on Television, hence, the viability of the theory to the study in context.

\section{Methodology}

The investigation was carried out through survey research method. In this method, we used questionnaire which became imperative due to the fact that the phenomenon bordering on this study cannot be subjected to a full laboratory experiment.

The population of this study was youth's residents in Port Harcourt City and Ikwerre Local Government Areas in Rivers State; however, due to the absence of the specific number of youths resident in the two LGA's, the total number of residents in the two Local Government Areas in the 2016 National Population Commission projection was used for this study, which is put at 756,60o and 265,400. This is predicated upon the fact that the figure is also inclusive of youths residing in the LGAs. Thus, the population of this study is 1,022,00o.

In other to determine the sample size, the Australian sample size calculator was used, hence the calculation is given below;

Confidence Level $\quad=95 \%$ 


$\begin{array}{ll}\text { Population Size } & =1,022,000 \\ \text { Confidence Interval } & =0.05880 \\ \text { Upper } & =0.55880 \\ \text { Lower } & =0.44120 \\ \text { Standard Error } & =0.03 \\ \text { Relative Standard Error }=6.00 \\ \text { Sample Size } & =278\end{array}$

Two hundred and seventy eight (278) persons were taken as respondents, where each of the local government area had one hundred and thirty nine respondents and these were taken as true representation and reflection of the entire population. As a result of this, findings made in the study were generalized based on the entire population.

The purposive sampling technique is used in selecting the sample for the research. This type of sampling include subject selected on the basis of specific inherent qualities and eliminates those that fail to meet the expected requirement. Hence, this non-probability method is regarded as the most appropriate for this research, as we are concerned with certain qualities - the youths, viewership and violence.

\section{Data Analysis/Discussion of Findings}

Two hundred and seventy eight copies of the questionnaire were distributed and administered to rural and urban communities with each having one hundred and thirty nine set of questions. In the end, 120 set of the questionnaire each was retrieved, thereby amounting to Two hundred and forty copies of the questionnaire in both rural and urban communities.

Table 1: Questionnaire Administration and Retrieval

\begin{tabular}{|l|c|c|c|}
\hline & No administered & Retrieved & Percentage \\
\hline Urban & 139 & 120 & $86 \%$ \\
\hline Rural & 139 & 120 & $86 \%$ \\
\hline Total & 278 & 240 & $86 \%$ \\
\hline
\end{tabular}

Source: Field Survey, 2017

As shown on the table 278 copies of the questionnaire were administered, but 240 copies were retrieved amounting, therefore to $86 \%$ of the return rate.

\subsection{Research Question 1: What is the extent of urban and rural youth's exposure to TV programmes?}

Table 2: Extent of youth's exposure to TV programmes

\begin{tabular}{|l|c|c|c|c|}
\hline Freq. & Urban & Percentage \% & Rural & Percentage \% \\
\hline To a great extent & 75 & $63 \%$ & 22 & $18 \%$ \\
\hline To a moderate extent & 30 & $25 \%$ & 48 & $40 \%$ \\
\hline To a low extent & 15 & $12 \%$ & 50 & $42 \%$ \\
\hline Total & 120 & $100 \%$ & 120 & $100 \%$ \\
\hline
\end{tabular}

Source: Field Survey, 2017

From the table above, 75 of the respondents from urban areas representing (63\%) said that they are to a great extent exposed to television programs, 30 representing $(25 \%)$ said that they are to a moderate 
extent exposed to tv programs, while 15 representing (12\%) said that they are to a low extent exposed to tv programs. On the other hand, 22 of the respondents in rural area representing (18\%) said that they are to a great extent exposed to tv programs, 48 representing $(40 \%)$ said that they are to a moderate extent exposed to tv programs, while 50 representing $(42 \%)$ said that they are to a low extent exposed to tv programs. This simply indicates that majority of respondents in the urban areas are greatly exposed to television programmes, while majority of those in the rural areas are to a low extent exposed to television programs. This means that youth's in the urban areas are more exposed to television programmes than their counterparts in rural areas.

\subsection{Research Question 2: Are the urban youth more prone to violence than their rural counterparts?}

Table 3: Prevalence of Violence

\begin{tabular}{|l|c|c|c|c|c|c|}
\hline & Freq. Yes & \% & Freq. No & $\%$ & Total & $\%$ \\
\hline Urban & 110 & $92 \%$ & 10 & $8 \%$ & 120 & $100 \%$ \\
\hline Rural & 100 & $83 \%$ & 20 & $17 \%$ & 120 & $100 \%$ \\
\hline
\end{tabular}

Source: Field Survey, 2017

Importantly, on the prevalence of violence arising from television viewing and vulnerability which is the main concern of the research question 2,110 respondents representing $92 \%$ were of the opinion that violence rate arising from television viewing invariably shows vulnerability.

On the other hand, 100 respondents representing $83 \%$ indicated that the prevalence of violence as a result of Television viewing was on the rural respondents. Moreover, in both the urban and rural respondents, aside from the 110 and 100 respondents who said that there is prevalence of violence. It is, therefore, indicative of the fact, from records, that violence arising from television viewing is prevalent more among urban than rural. However, it exists in all the residents, thereby showing vulnerability to television viewing in its entirety.

4.3 Research Question 3: Do youths in urban areas exhibit traits of violence portrayed on TV on unsuspected members of the public?

Table 4: Exhibition of Violence Traits by Youth

\begin{tabular}{|l|c|c|c|c|c|c|c|c|}
\hline & Freq. Yes & \% & Freq. No & \% & Void & $\%$ & Total & $\%$ \\
\hline Urban & 40 & $33 \%$ & 60 & $50 \%$ & 20 & $17 \%$ & 120 & $100 \%$ \\
\hline Rural & 38 & $32 \%$ & 50 & $42 \%$ & 32 & $26 \%$ & 120 & $100 \%$ \\
\hline
\end{tabular}

Source: Field Survey, 2017

Research question 2 focuses on respondents' view of youths themselves exhibiting violence, owing to television viewing, thereby explaining their vulnerability. To this end, in the urban setting, 40 respondents, representing $33 \%$ of the population accepted that they have exhibited violence arising from television viewing, while 60 respondents, representing $50 \%$ said they have never exhibited violence, as a result of television viewing. Conversely, in the rural setting, 38 respondents accepted they exhibited violence in one way or the other, which represents $32 \%$ of the respondents, while those who said no to exhibiting violence were put at 50 respondents representing $42 \%$. However, 20 and 32 had voided questions representing 17 and $21 \%$ of the population.

Crime is regularly exhibited from records, from youths in the urban areas than in rural areas, due to viewing of television violent programmes as exemplified in the table above. 
4.4 Research Question 4: To what extent is the effect of TV violence on youth's behaviour in urban and rural areas?

Table 5: Extent of Effect of TV Violence on Youths

\begin{tabular}{|l|c|c|c|c|c|c|c|c|}
\hline & Great Extent & $\%$ & Moderate Extent & $\%$ & Low Extent & $\%$ & Total & $\%$ \\
\hline Urban & 90 & $75 \%$ & 20 & $17 \%$ & 10 & $8 \%$ & 120 & $100 \%$ \\
\hline Rural & 65 & $54 \%$ & 40 & $33 \%$ & 15 & $13 \%$ & 120 & $100 \%$ \\
\hline
\end{tabular}

Source: Field Survey, 2017

Table 5 sought to determine the extent to which violence on television affect the behaviour of youths in both urban and rural areas. Hence, in the urban area, 90 respondents representing $75 \%$ said that television violence affects the behaviour of youths to a great extent, 20 of the respondents representing $17 \%$ said to a moderate extent, while 10 of the respondents representing $8 \%$ said to a low extent. On the other hand, in the rural setting 65 of the respondents representing $54 \%$ said that television violence affects the behaviour of youths to a great extent, 40 respondents representing $33 \%$ said to a moderate extent, while 15 of the respondents said to a low extent. Based on the above data, majority of the respondents in the urban area attest to the fact that television violence affects the behaviour of youths to a great extent. This finding is also in line with the findings gotten in the rural area. Consequently, television violence to a great extent affects the behaviour of youths both in the urban and rural settings.

\subsection{Findings}

1) Youths in urban areas are greatly exposed to television programmes, while those in the rural areas are to a low extent exposed to television programmes.

2) Youths in the urban areas show more interest in television viewing than their rural counterparts.

3) Violence arising from Television viewing is more pronounced and prevalent among the urban settler than the rural settlements. To this end, there is violence arising from Television viewing.

4) Youth access violence from several means other than the conventional means of using Television. Therefore, it was discovered that they use other means like; Internet, Video, Phones, Theatre, Cable TV and above all, Television. This underscores the fact that with these forms, there is direct access to violence via viewing, and this is more pronounced in the urban areas.

5) In the same vein, on whether television stations are mostly patronized for violence; the study found that the urban dwellers rely on cable mostly for violence while the rural rely on Television stations like Silverbird and AlT respectively.

\section{Summary/Conclusion}

This study is geared towards ascertaining the vulnerability of television violence, as a result of television viewing among youths in urban and rural audiences in Rivers State. Therefore, after a careful study, a lot of observations were made on both residences, which form the basis for a comparison of the two groups of audiences. To this end, it is imperative to state that audience in urban areas show a lot of interest in television viewing than their rural counterparts, which could be attributed to the proliferation of electronic devices and other media forms other than the television. It is also instructive to opine that violence arising from TV viewing among urban and rural audience is more prevalent in urban than in the rural. This is evident in the antisocial behaviour usually 
exhibited by the youths and, it is on the increase in the urban than the rural, judging from the outcome of the study.

These attitude exhibited by the youths are garnered by the youths from the television, internet, phones, theatres cable TV etc. The litany of access to information by the youths has facilitated their patronage, thereby acting as a catalyst for their change in behaviour due to television viewing. These behaviours are prevalent in urban than rural residents, as they enjoy the accessibility to other forms of information acquisition which are not inherent in the rural setting. However, they tend to measure up gradually with establishment of cybercafé in LGA headquarters and the acquisition of new mobile phones imbued with some facilities to encourage the access to information other than from the television.

\section{Recommendations}

(i) Since there is the tendency of the adolescent and youths to imitate what they see on TV, parents and elder siblings should limit their children/ward/ siblings exposure to TV violence or other portrayals of actions that would be dangerous for them to imitate. Parents should rather provide them with educational TV programmes.

(ii) University and industry researchers should intensify effort in redirecting the youths with mode of teaching and problem solving techniques to redirect the youths and make them abandon negative attributes of the TV violence.

(iii) Parental mediation from early children is highly solicited and canvassed to avoid the jumping into the scary form of TV viewing as they grow up, as what they learn as children remain till adulthood. Secondly, for younger school aged children, parents should restrict the amount and types of programme children watch, in order to reduce their children fear and aggressiveness, which leads to violence growing up.

(iv) Government should galvanize their regulatory agencies on the adherence to x-rated films for ages and viewers.

\section{References}

Awake (2006, October). Tv — The 'subtle instructor'

Baran. S. J. (2009). Introduction to mass communication: Media literacy and culture (5th ed). Boston: McGraw Hill Higher Education.

Chieme, A. and Usua, N. (2008). Reality television and youth development in Nigeria. In international journal of communication: No 9 December, 2008.

Dominick. J.R. (2007). The dynamics of mass communication: Media in digital age. (9th ed.) Boston: McGraw Hill

Donohue, T.R., Henke, L.L. and Morgan, L.A. (1988). The impact of television's role model on physically abused children. Child study journal 18(3), 233-247

Jeffrey, G., Cohen, P., Smaites, E.M., Kasen, S. \& Brook, J.S.: Television viewing and aggressive behaviour during adolescence and adulthood. Retrieved from http:/ /daphae.palomar.edu/pjacoby retrieved on 21/o4/2010

Noguera, P. (2010). Reducing and preventing youth violence: An analysis of causes and an assessment of successful programs. Bar Keley, California. In motion magazine.comNPC production (1995-2010) (web material) retrieved 21/04/2010

Potter, W.J. and Tomasello, T.K. (2003). Building upon the experimental design in media violence research: The importance of including receiver interpretation. In international journal of communication. June 2003 Vol.53.No.2.

Saito, S. (2007). Television and the cultivation of gender - role 'attitude in Japan: Does television contribution to maintenance of the status quo? Journal of communication. Vol.57, No.3, Sept; 2007 pp. $511-531$

Rodman, G. (2006). Mass media in a changing world. Boston: McGraw Hill Higher Education.

Vivian, J. (2007). The media of mass communication (8th ed). USA: Pearson Education Inc. 